\title{
Role of TP53 Gene Polymorphism in Male Infertility
}

\author{
Rekha Govindhasamy ${ }^{1}$, Paramesh Govindhasamy ${ }^{2}$, Rajitha Vanga ${ }^{3}$, Pushpa Burute ${ }^{4}$
}

\begin{abstract}
Introduction: The TP53 gene is located on chromosome 17p13.1.P53 gene considered as the guardian of the genome belongs to a threemembered gene family $p 53, p 63$, and $p 73 .{ }^{1} p 53$ plays a vital role in human cancer and whose mutation was observed in nearly $50 \%$ of cancer all around the world. In the present study, genotype distribution was assessed in 147 infertile males, fertile males, and the associations of TP53 Arg72Pro polymorphism with hormonal and seminal parameters were investigated.

Materials and methods: A total of 147 infertility men and 150 fertile men were taken for the study. Polymerase chain reaction (PCR) was carried out to amplify the exon 4 of the human $p 53$ CODON 72 genotyping was performed by restriction fragments length polymorphism (RFLP).

Results: In summary, the AA genotype and the A allele are significantly associated with azoospermic men when compared to fertile men.

Conclusion: The study found preliminary evidence demonstrated that the TP53 gene Arg72 Pro polymorphism contributes significant association to male infertility.

Aim and objective: To analyze the association of $p 53$ gene polymorphism in male infertility cases in the study population.

Keywords: Azoospermia, Male infertility, p53 gene polymorphism, Polymorphism, TP53 gene.

International Journal of Infertility and Fetal Medicine (2021): 10.5005/jp-journals-10016-1218
\end{abstract}

\section{INTRODUCTION}

Infertility affects $15 \%$ of married couples. ${ }^{2}$ During the process of spermatogenesis, spermatocytes with synaptic errors are eliminated by apoptosis are found to be $p 53$ dependent. ${ }^{3}$ The $p 53$ tumor suppressor protein is expressed in the testis and $p 53$ plays a vital role in meiotic stages confined to the pachytene primary spermatocytes. ${ }^{4}$ Sjoblom and Lahdetie (1996) observed the expression of $p 53$ in normal and gamma-irradiated rat testis which shows the role for $p 53$ in meiotic recombination and repair. Depletion of $p 53$ from germ cells results in an increased incidence of unrepaired DNA breaks in pachytene spermatocytes and increased numbers of caspase-3 positive (apoptotic) germ cells. ${ }^{5}$ Paul et al. demonstrated that deletion of Erccl (excision repair cross-complementing gene 1), Msh2 (MutS homolog 2, involved in mismatch repair pathway), and $p 53$ can have differential but overlapping effects on germ cell function and sperm production in which gene mutations can have an impact on male fertility. ${ }^{6}$ The following are some of the apoptotic-related gene products influenced by $p 53$ that induces apoptosis by intrinsic or extrinsic pathways. PIDD ( $p 53$-induced protein with death domain), PERP ( $p 53$ apoptosis effector related to PMP-22), Apaf-1 (apoptotic protease- 69 activating factor-1), Scotin, a novel $p 53$-inducible proapoptotic protein located in the endoplasmic reticulum and the nuclear membrane, and p53AIP1 (p53-regulated apoptosis-inducing protein (1). A cohort study done by Eisenberg et al., to evaluate the cancer incidence in infertile men with azoospermia and infertile men without azoospermia with a mean age of 35.7 years revealed that infertile men with azoospermia had 2.2-fold cancer risk compared to infertile men without azoospermia. ${ }^{7}$ Men with azoospermia have an increased risk of subsequently developing cancer, suggesting a possible common etiology between azoospermia and cancer development.

\section{Materials and Methods}

\section{Inclusion Criteria}

- Cases with idiopathic causes for male infertility with a female partner found normal after a gynecological examination.
${ }^{1}$ Department of Anatomy, Rajas Dental College and Hospital, Kavalkinaru, Tirunelveli, Tamil Nadu, India

${ }^{2,4}$ Department of Anatomy, BKL Walawalkar Rural Medical College, Sawarde, Ratnagiri, Maharashtra, India

${ }^{3}$ Department of Anatomy, Vinayaka Mission's Kirupananda Variyar Medical College and Hospitals, Salem, Tamil Nadu, India

Corresponding Author: Rekha Govindhasamy, Department of Anatomy, Rajas Dental College and Hospital, Kavalkinaru, Tirunelveli, Tamil Nadu, India, Phone: +91 9940937386, e-mail: rekha.anatomy@ gmail.com

How to cite this article: Govindhasamy R, Govindhasamy P, Vanga R, et al. Role of TP53 Gene Polymorphism in Male Infertility. Int J Infertil Fetal Med 2021;12(2):44-48.

Source of support: Nil

Conflict of interest: None

- Cases and controls with no recent history of illness, fever, or drug intake.

\section{Exclusion Criteria}

- Cases whose semen samples contained $>1 \times 10^{6}$ million leukocytes and with high viscosity.

- Cases having varicocele, hydrocele, cryptorchidism, bilateral absence of vas deferens, and any other congenital abnormalities.

\section{p53 Gene Polymorphism}

Human genomic DNA was isolated from the lymphocytes using modified Miller's protocol. ${ }^{8}$ Agarose of $0.7 \%$ was found to be appropriate for electrophoresis of human genomic DNA. Electrophoresis was carried out at $50 \mathrm{~V}$ for 2 hours. The gel was viewed under a UV-transilluminator (UVitec, Lark innovative Inc.), and photographs were taken using Nikon cool pix 4500, digital camera.

(c) Jaypee Brothers Medical Publishers. 2021 Open Access This article is distributed under the terms of the Creative Commons Attribution 4.0 International License (https://creativecommons.org/licenses/by-nc/4.0/), which permits unrestricted use, distribution, and non-commercial reproduction in any medium, provided you give appropriate credit to the original author(s) and the source, provide a link to the Creative Commons license, and indicate if changes were made. The Creative Commons Public Domain Dedication waiver (http://creativecommons.org/publicdomain/zero/1.0/) applies to the data made available in this article, unless otherwise stated. 


\section{Polymerase Chain Reaction}

Polymerase chain reaction (PCR) was carried out to amplify the exon 4 of the human $p 53$ CODON72 gene which has the C72G polymorphism.

Genotyping was performed by restriction fragments length polymorphism (RFLP) analysis. Polymerase chain reaction amplicons were digested with BstUl enzyme. In the homozygous mutant, BstU lenzyme recognizes 5'CGCG3' site and digested into two fragments (175 and 132 bp). In homozygous normal, BstU / will not recognize any site (no digestion), and produce a single fragment (307 bp). In the heterozygous mutant, BstU I produces three fragments (307, 175 , and $132 \mathrm{bp}$ ).

The digested PCR amplified products were run on $2 \%$ agarose gel. $800 \mathrm{mg}$ of agarose was melted in $40 \mathrm{~mL}$ of $1 \times$ TBE buffer. 8.0 $\mu \mathrm{L}$ of the sample was added with $2 \mu \mathrm{L}$ of loading dye which was sufficient for the analysis of the digested products. Electrophoresis was carried out at $50 \mathrm{~V}$ for 2 hours. The restricted samples in the gel that is run along with the marker were viewed under UV-transilluminator and photographed. Then, the genotypes are noted.

\section{PCR Amplification}

The DNA samples were processed for studying the presence of Arg72Pro polymorphism in the $p 53$ gene. The samples were amplified using the primers TD7 and TD8 and the temperature was standardized to $66.3^{\circ} \mathrm{C}$, an intense specific band of the expected size 307 bp with the absence of non-specific bands was observed (Fig. 1).

\section{RFLP Analysis}

The restriction digestion using the Bstu I (Bacillus stearothermophilus) enzyme was carried out for all the amplicons. The agarose gel suitable for the restriction digestion using the Bstu lenzyme was the analysis of the digested products was standardized to $2 \%$ agarose. The expected size of the digested products was observed. In the homozygous mutant, Bstu l enzyme recognizes 5' CG/CG 3' site and produces two fragments (175 and 132 bp) (Fig. 2). In normal, Bstu I enzyme will not recognize any site. In heterozygous mutant type Bstu, I enzyme produces three fragments (307, 175, and $132 \mathrm{bp}$ ) (Fig. 2). The frequency of the different genotypes, CC, CG, and GG has been compared between infertile men and fertile men (Table 1).

\section{Results}

\section{The TP53 Arg72Pro polymorphism}

\section{Genotype and Allele Frequencies}

The Arg72Pro polymorphism of the TP53 gene was denoted as A and $P$, respectively. Tables 2 and 3 show the distributions of genotypes of

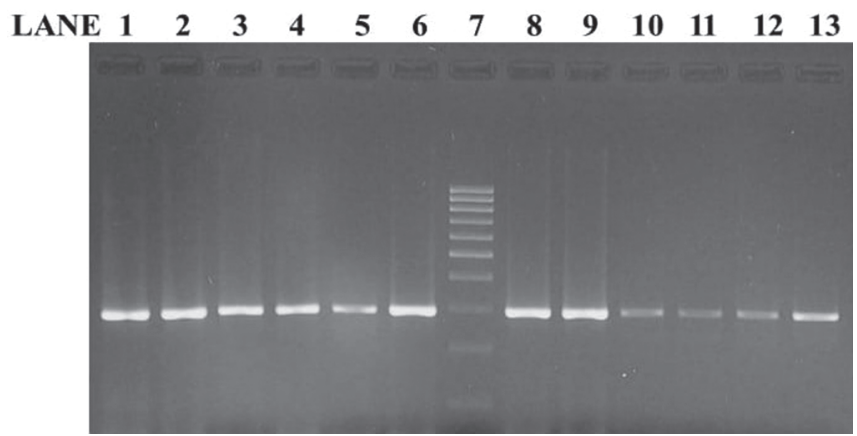

Fig. 1: Agarose gel picture showing the PCR amplification of TP53 gene
TP53 Arg72Pro polymorphism. The TP53 genotype distribution was in agreement with Hardy-Weinberg equilibrium within the infertile men (azoospermic, oligospermic, oligospermic, teratozoospermia men) and the control group (fertile men) $(p<0.05)$. Among the genotypes, AP was most common (52.7\% infertile and $48.3 \%$ in infertile male patients). The AA genotype frequency was found to be higher in infertile male patients (36.7\%) when compared to controls $(30.7 \%)$, even though no significant differences were observed between the groups. No significant differences were observed with the TT genotype between infertile men (15.0\%) when compared to controls (16.7\%) (Table 2).

Table 3 shows the distribution of genotypes between the control and different subgroups of infertile men (patient groups). The AP genotype was found to be more common between the groups. The frequency of the AA genotype was found to significantly higher in azoospermic men (59.1\%) when compared to controls ( $p=0.002$ ) (Table 4 ) and no significant differences were observed when compared to oligospermic (32.4\%), severe oligospermic (30.2\%), oligo/astheno/teratozoospermic men (15.4\%) groups. The PP genotype was found to be lower in azoospermic men $(9.1 \%)$ when compared to other groups showing a significance ( $p=0.030$ ) (Table 4).

Overall significant difference was observed between azoospermic men and the control group $\left(\chi^{2}=11.80\right.$, d.f. $=2, p$ $=0.003$ ). The allele frequencies showed a significant difference between azoospermic men $(p=0.002)$ and the control group. However, there were no significant differences between the control and other subgroups of infertile men (Table 3).

\section{Odds Ratios}

As a significant association was obtained while comparing azoospermic men with fertile men, odds ratios were computed for comparison of various genotypes models between these groups (Table 4). The relative risk was observed to be twice as high in subjects with A allele carriers when compared to P allele carriers. Three of the five genotype comparisons viz., AA vs PP (OR 3.53, $95 \% \mathrm{Cl} 1.11-11.27 ; p=0.033)$, AA vs AP (OR 3.19, 95\% Cl 1.51-6.72; $p$ $=0.002)$, and AA vs AP + PP (OR 3.27, 95\% Cl 1.63-6.54; $p=0.001)$ showed significant association among azoospermic men. The odds ratio for $\mathrm{A}$ vs $\mathrm{P}$ allele comparison attained statistical significance $(p=0.004)$.

None of the genotype comparisons showed significant association in azoospermic men (Table 5).

\section{Discussion}

Several studies on animals have shown that $p 53$ is evolutionarily conserved. The $p 53$ protein is reported transiently activated in

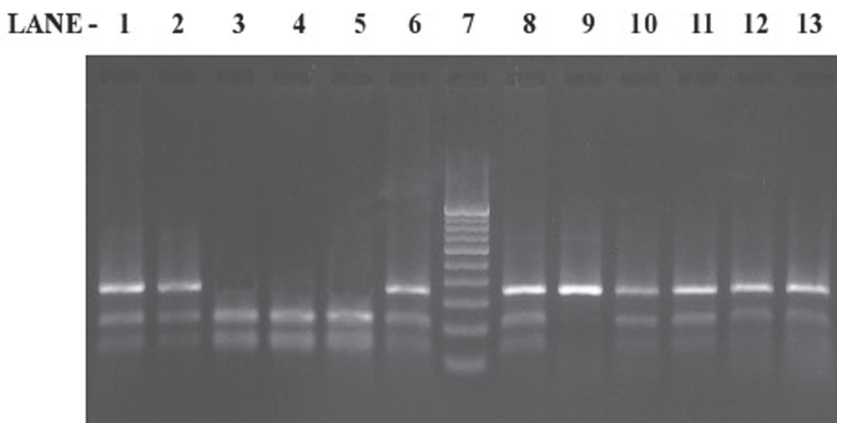

Fig. 2: Agarose gel picture showing the RFLP analysis of TP53 gene 
Table 1: Primer sequence of TP53 gene

\begin{tabular}{lllllll}
\hline S. no. & Primer name & Primer sequence & Primer length & GC\% & $\operatorname{Tm}^{\circ} \mathrm{C}$ & Product size \\
\hline 1 & (Forward primer) & 5' CACCCATCTACAGTCCCCCTTGC 3' & $23 \mathrm{mer}$ & 60.9 & 60 & $307 \mathrm{bp}$ \\
2 & (Reverse primer) & 5' CTCAGGGCAACTGACGGTGCAAG 3' & $23 \mathrm{mer}$ & 60.9 & 60 & $307 \mathrm{bp}$ \\
\hline
\end{tabular}

Table 2: Genotype and allele frequencies of Arg72Pro polymorphism (rs1042522) at TP53 gene: all subjects

\begin{tabular}{lllllll}
\hline & \multicolumn{3}{c}{ Genotype frequency } & & & \multicolumn{2}{c}{ Allele frequency } \\
\cline { 2 - 3 } Subjects & $A A$ & $A P$ & $P P$ & $\chi^{2} H W$ & & $P$ \\
\hline $\begin{array}{l}\text { Fertile men } \\
\text { All } n\end{array}$ & 46 & 79 & 25 & 0.830 & 0.570 & 0.430 \\
$\begin{array}{l}\text { Infertile men } \\
\text { All } n\end{array}$ & 30.7 & 52.7 & 16.7 & & & \\
$\%$ & 54 & 71 & 22 & 0.029 & 0.609 & 0.391 \\
\hline
\end{tabular}

$\mathrm{AA}$, wild-type homozygote; $\mathrm{AP}$, heterozygote; $\mathrm{PP}$, mutant homozygote

$p\left(\chi_{2 \mathrm{df}}^{2}\right)$ independence of genotype frequencies by the groups compared (fertile vs infertile men) $\chi^{2}=1.23, p=0.541$.

$p\left(\chi_{1 \mathrm{df}}^{2}\right)$ men $\chi^{2}=0.93, p=0.336$

Table 3: Genotype and allele frequencies of Arg72Pro polymorphism (rs1042522) at TP53 gene: fertile vs subgroups of infertile men

\begin{tabular}{|c|c|c|c|c|c|c|}
\hline \multirow[b]{2}{*}{ Subjects } & \multicolumn{3}{|c|}{ Genotype frequency } & \multirow[b]{2}{*}{$\chi^{2} H W$} & \multicolumn{2}{|c|}{ Allele frequency } \\
\hline & $A A$ & $A P$ & $P P$ & & $A$ & $P$ \\
\hline \multicolumn{7}{|l|}{ Fertile men } \\
\hline All $n$ & 46 & 79 & 25 & 0.830 & 0.570 & 0.430 \\
\hline$\%$ & 30.7 & 52.7 & 16.7 & & & \\
\hline \multicolumn{7}{|l|}{ Infertile men (subgroups) } \\
\hline All $n$ & 54 & 71 & 22 & 0.029 & 0.609 & 0.391 \\
\hline$\%$ & 36.7 & 48.3 & 15.0 & & & \\
\hline Azoospermic $n$ & $26^{\mathrm{a}}$ & $14^{\mathrm{a}}$ & $4^{\mathrm{a}}$ & 1.010 & $0.750^{e}$ & $0.250^{\mathrm{e}}$ \\
\hline$\%$ & 59.1 & 31.8 & 9.1 & & & \\
\hline Oligospermic $n$ & $11^{\mathrm{b}}$ & $15^{\mathrm{b}}$ & $8^{\mathrm{b}}$ & 0.417 & 0.544 & 0.456 \\
\hline$\%$ & 32.4 & 44.1 & 23.5 & & & \\
\hline Severe oligospermic $n$ & $13^{c}$ & $25^{c}$ & $5^{c}$ & 1.798 & 0.593 & 0.407 \\
\hline$\%$ & 30.2 & 58.1 & 11.6 & & & \\
\hline Oligo/astheno/teratozoospermic $N$ & $4^{d}$ & $17^{d}$ & $5^{d}$ & 2.493 & 0.481 & 0.519 \\
\hline$\%$ & 15.4 & 65.4 & 19.2 & & & \\
\hline
\end{tabular}

$\mathrm{AA}$, wild-type homozygote; $\mathrm{AP}$, heterozygote; $\mathrm{PP}$, mutant homozygote

${ }^{\mathrm{a}} \chi^{2}=11.80, \mathrm{df}=2, p=0.003$ for genotype frequencies in control vs azoospermic men

$\mathrm{b}^{2}=1.15, \mathrm{df}=2, p=0.563$ for genotype frequencies in control vs oligospermic men

${ }^{c} \chi^{2}=0.73, \mathrm{df}=2, p=0.693$ for genotype frequencies in control vs severe oligospermic men

$\mathrm{d}_{\chi} \chi^{2}=2.56, \mathrm{df}=2, p=0.278$ for genotype frequencies in control vs oligo/astheno/teratozoospermic men

$\mathrm{e}^{2} \chi^{2}=9.27, \mathrm{df}=1, p=0.002$ for allele frequency in control vs azoospermic men

early spermatocytes peaking between the leptotene and zygotene stages. ${ }^{9}$ A very recent and additional function of $p 53$ in reproduction has been reported in mice showing that $p 53$ regulates blastocyst implantation and maternal reproduction through regulation of leukemia inhibitory factor (LIF). ${ }^{10}$ Leukemia inhibitory factor, a pleiotropic cytokine is said to be transiently expressed in the uterus on the onset of implantation. Studies have shown that $\mathrm{LIF}^{-/-}$mice to be defective in reproduction and failure of implantation and that $p 53^{-/-}$mouse had impaired implantation because of decrease LIF levels in the uterine. Reversal and enhanced implantation of impaired reproduction by exogenous injections of LIF into $p 53^{-1-}$ female mice indicated that LIF is a target gene of $p 53$ in reproduction.
Table 4: Genotype and allele frequencies of Arg72Pro polymorphism (rs1042522) at TP53 gene: fertile vs azoospermic men

\begin{tabular}{llll}
\hline Subjects & Fertile men & Azoospermic men & p value \\
\hline Genotypes & 150 & 44 & \\
Arg/Arg & 46 & 26 & 0.002 \\
& $30.7 \%$ & $59.1 \%$ & \\
Arg/Pro & 79 & 14 & 0.867 \\
& $52.7 \%$ & $31.8 \%$ & \\
Pro/Pro & 25 & 4 & 0.030 \\
& $16.7 \%$ & $9.1 \%$ & \\
\hline
\end{tabular}

OR of Arg allele is $2.26(95 \% \mathrm{Cl}, 1.33-3.86)$ 
Role of TP53 Gene Polymorphism in Male Infertility

Table 5: Odds ratios (OR) and 95\% confidence intervals (Cl) of azoospermic men according to TP53 (rs1042522) genotype

\begin{tabular}{|c|c|c|c|c|c|c|c|c|}
\hline \multirow{2}{*}{$\begin{array}{l}\text { Genotypic } \\
\text { combinations }\end{array}$} & \multirow[b]{2}{*}{$p$ value $\left(\chi_{2 d f}^{2}\right)$} & \multirow[b]{2}{*}{ OR } & \multicolumn{2}{|c|}{ 95\% C.I. } & \multirow[b]{2}{*}{$p$ value $e^{\#}\left(\chi_{2 d f}^{2}\right)$} & \multirow[b]{2}{*}{$O R^{\#}$} & \multicolumn{2}{|c|}{ 95\% C.I. } \\
\hline & & & Lower & Upper & & & Lower & Upper \\
\hline \multicolumn{9}{|c|}{ Co-dominant model } \\
\hline AP vs PP & 0.867 & 1.108 & 0.334 & 3.673 & 0.966 & 1.026 & 0.307 & 3.434 \\
\hline AA vs PP & 0.033 & 3.533 & 1.108 & 11.267 & 0.048 & 3.256 & 1.011 & 10.485 \\
\hline$A A$ vs $A P$ & 0.002 & 3.19 & 1.514 & 6.715 & 0.003 & 3.15 & 1.490 & 6.675 \\
\hline \multicolumn{9}{|c|}{ Dominant model } \\
\hline $\begin{aligned} & A A \text { vs AP } \\
+ & P P\end{aligned}$ & 0.001 & 3.266 & 1.631 & 6.537 & 0.001 & 3.191 & 1.586 & 6.421 \\
\hline \multicolumn{9}{|c|}{ Recessive model } \\
\hline $\begin{array}{l}A A+A P \\
\text { vs } P P\end{array}$ & 0.223 & 2.0 & 0.657 & 6.092 & 0.286 & 1.843 & 0.599 & 5.668 \\
\hline
\end{tabular}

OR, odds ratio; $\chi^{2}$, Chi-square; Cl, confidence interval; $\mathrm{p}$, probability; \#, age adjusted

The calculation was performed following a recessive genotype model for Arg/Arg vs Arg/Pro and Pro/Pro

The calculation was performed for Arg/Arg and Arg/Pro vs Pro/Pro

Although these factors are said to play a role in male infertility with spermatogenesis failure, several recent studies have focused on single-nucleotide polymorphisms (SNPs) and their association with human infertility.

Tumor suppressor protein TP53 ( $p 53)$, is an important gene and is said to play a pivotal role in modulating cell growth, division, and apoptosis. ${ }^{11}$ It is located on chromosome 17 p13 and encodes a 53-kDa nuclear phosphoprotein. Around 13 variants have been reported that harbor in TP53 with the most important one being the $\mathrm{G} \rightarrow \mathrm{C}$ transversion at the second position of the codon 72 in exon 4 that encodes a proline $(P)$ or arginine $(R)$, resulting in differences in structure and function. ${ }^{12}$

The $p 53$ protein is said to play a crucial role in maintaining genomic stability in somatic cells and thereby preventing tumor formation..$^{13}$ The p53 P72 allele is weaker in inducing apoptosis and in suppressing cellular transformation when compared to the R72 allele. Similarly, individuals with the p53 P72 allele have been reported to be at an increased risk for cancer compared to the $p 53$ R72 allele (Murphy, 2006) and that the P72 allele was found to be enriched in patients with recurrent implantation failure in vitro fertilization (IVF) clinical setup. ${ }^{14}$ Recently, a meta-analysis showed that the P72 allele to be associated with the risk of endometriosis in Asians leading to infertility in females ${ }^{15}$ and also with type 2 diabetes in an Italian population ${ }^{16}$

Also, several other SNPs have been identified in genes at critical nodes in the $p 53$ pathways that include $\mathrm{p} 53, \mathrm{Mdm} 2, \mathrm{Mdm} 4$, and Hausp influencing cancer susceptibility. ${ }^{10,17-19}$ Thus, the possibility of these genes involving the $p 53$ pathway undergoing selection might also involve in influencing male infertility.

In the present study, we examined the genotype distribution in 147 infertile male patients and 150 controls. As known, the frequency distributions of genetic polymorphisms often vary across diverse ethnic backgrounds and geographic locations, yielding conflicting results. The frequency of the AA genotype was found to be $30.7 \%$ in our population which is near equal to the Chinese population ${ }^{20}$ and different from Iranians. ${ }^{21}$

No significant associations were observed between patients and controls which was similar to other studies on male infertility., ${ }^{91}$ But when the infertile men were divided into different groups, we observe a significant association of the $p 53$ Arg allele to be associated with male infertility. A recent meta-analysis by Chan et al. also did not observe any significant association of the p53 polymorphism Arg allele with azoospermic males. ${ }^{22}$ Similar studies that were conducted on infertile men did not find any association with azoospermic men ${ }^{20,21}$ as all the above three studies were not subgrouped and thus no clear association of TP53 codon 72 polymorphism with idiopathic infertility.

In our study, when subgroups of subfertile men were analyzed, azoospermic men were found to be significantly associated with male infertility. The Arg allele (59.1\%) was found to be significantly associated $\left(\chi^{2}=9.27, \mathrm{df}=1, p=0.002\right)$. A similar association was observed in men with idiopathic infertility showing an increased frequency of the Arg allele (62.5\%) in a Chinese population. ${ }^{23}$

When odds ratios were computed between azoospermic men and controls. Out of all five genotypic combination, the co-dominant models $A A$ vs $P P(O R=3.53 ; C l: 1.11-11.27 ; p=0.03)$, $A A$ vs PA (OR $=3.19 ; \mathrm{Cl}: 1.51-6.72 ; p=0.002)$, and the dominant model AA vs AP + PP (OR = 3.27; Cl: 1.63-6.54; $p=0.001)$ showed significant association when compared with controls. A similar kind of association was observed in the azoospermic group in Chinese males (OR $=1.988 ; \mathrm{Cl}: 1.26-3.14 ; p=0.003)$.

We did not observe any significant difference between the oligospermic, severe oligozoospermia, oligo/astheno/ teratozoospermic group, and controls in the rs1042522 frequency. Thus, this clearly shows that the Arg allele to have a dominant effect in South Indian male infertility and especially on a subgroup of azoospermic males. Our present work also did not reveal any significant association with any other subject characteristics and other clinical variables.

\section{Conclusion}

Our study showed that the Arg allele frequency of TP53 to be associated with azoospermic males and male infertility. A recent study has shown a relationship between $p 53$ codon $72 \mathrm{Arg} / \mathrm{Arg}$ genotype and increased apoptosis that contributes to spermatozoa motility and male fertility in men with varicocele. Male infertility is a heterogeneous disorder, with multiple environmental factors and numerous genetic factors contributing to impaired spermatogenesis warranting a better insight into the biological mechanisms of $p 53$ with male infertility in humans. Thus study showed that the TP53 gene Arg72Pro polymorphism contributes significant association to male infertility in the South Indian population. 


\section{References}

1. Schmale $H$, Bamberger $C$. A novel protein with strong homology to the tumor suppressor p53. Oncogene 1997;15(11):1363-1367. DOI: 10.1038/sj.onc.1201500.

2. Poongothai J, Gopenath TS, Manonayaki S, et al. Genetics of human male infertility. Singapore Med J 2009;50(4):336-347.

3. Odorisio T, Rodriguez TA, Evans EP, et al. The meiotic checkpoint monitoring synapsis eliminates spermatocytes via p53-independent apoptosis. Nat Genet 1998;18(3):257-261. DOI: 10.1038/ng0398-257.

4. Schwartz D, Goldfinger N, Rotter V. Expression of p53 protein in spermatogenesis is confined to the tetraploid pachytene primary spermatocytes. Oncogene 1993;8(6):1487-1494.

5. Sjöblom T, Lähdetie J. Expression of $\mathrm{p} 53$ in normal and $\gamma$-irradiated rat testis suggests a role for $\mathrm{p} 53$ in meiotic recombination and repair. Oncogene 1996;12(12):2499-2505.

6. Paul C, Povey JE, Lawrence NJ, et al. Deletion of genes implicated in protecting the integrity of male germ cells has differential effects on the incidence of DNA breaks and germ cell loss. PLoS ONE 2007;2(10):e989. DOI: 10.1371/journal.pone.0000989.

7. Eisenberg $M L$, Betts $P$, Herder $D$, et al. Increased risk of cancer among azoospermic men. Fertil Steril 2013;100(3):681-685. DOI: 10.1016/j. fertnstert.2013.05.022.

8. Miller SA, Dykes DD, Polesky HF. A simple salting out procedure for extracting DNA from human nucleated cells. Nucleic Acids Res 1988;16(3):1215. DOI: 10.1093/nar/16.3.1215.

9. Lu WJ, Chapo J, Roig I, et al. Meiotic recombination provokes functional activation of the p53 regulatory network. Science 2010;328(5983):1278-1281. DOI: 10.1126/science.1185640.

10. Kang H-J, Feng Z, Sun Y, et al. Single-nucleotide polymorphisms in the 053 pathway regulate fertility in humans. Proc Natl Acad Sci U S A 2009;106(24):9761-9766. DOI: 10.1073/pnas.0904280106.

11. Levine AJ. P53, the cellular gatekeeper for growth and division. Cell 1997;88(3):323-331. DOI: 10.1016/s0092-8674(00)81871-1.

12. Pietsch EC, Humbey O, Murphy ME. Polymorphisms in the p53 pathway. Oncogene 2006;25(11):1602-1611. DOI: 10.1038/ sj.onc.1209367.

13. Levine AJ, Hu W, Feng Z. The P53 pathway: what questions remain to be explored? Cell Death Differentiat 2006;13(6):1027-1036. DOI: 10.1038/sj.cdd.4401910.
14. Kay C, Jeyendran RS, Coulam CB. p53 tumour suppressor gene polymorphism is associated with recurrent implantation failure. Reprod Biomed Online 2006;13(4):492-496. DOI: 10.1016/s14726483(10)60635-9.

15. Li J, Chen Y, Mo Z, et al. TP53 Arg72Pro polymorphism (rs1042522) and risk of endometriosis among Asian and Caucasian populations. Eur J Obstet Gynecol Reprod Biol 2015;189:73-78. DOI: 10.1016/j. ejogrb.2015.03.026.

16. Bonfigli AR, Sirolla C, Testa R, et al. The p53 codon 72 (Arg72Pro) polymorphism is associated with the degree of insulin resistance in type 2 diabetic subjects: a cross-sectional study. Acta Diabetol 2013;50(3):429-436. DOI: 10.1007/s00592-012-0450-x.

17. Dumont $\mathrm{P}$, Leu JIJ, Della Pietra $\mathrm{AC}$, et al. The codon 72 polymorphic variants of $\mathrm{p} 53$ have markedly different apoptotic potential. Nat Genet 2003;33(3):357-365. DOI: 10.1038/ng1093.

18. Bond $\mathrm{GL}, \mathrm{Hu} \mathrm{W}$, Bond $\mathrm{EE}$, et al. A single nucleotide polymorphism in the MDM2 promoter attenuates the $\mathrm{p} 53$ tumor suppressor pathway and accelerates tumor formation in humans. Cell 2004;119(5):591-602. DOI: 10.1016/j.cell.2004.11.022.

19. Bergamaschi D, Samuels Y, Sullivan A, et al. iASPP preferentially binds p53 proline-rich region and modulates apoptotic function of codon 72-polymorphic p53. Nat Genet 2006;38(10):1133-1141. DOI: 10.1038/ ng1879.

20. Huang C, Liu W, Ji GX, et al. Genetic variants in TP53 and MDM2 associated with male infertility in Chinese population. Asian J Androl 2012;14(5):691-694. DOI: 10.1038/aja.2012.39.

21. Mashayekhi F, Hadiyan SP. A single-nucleotide polymorphism in TP53 may be a genetic risk factor for Iranian patients with idiopathic male infertility. Andrologia 2012;44(Suppl 1):560-564. DOI: 10.1111/j.14390272.2011.01227.x.

22. Chan $Y$, Jiang $H$, Ma L, et al. No association of TP53 codon 72 SNP with male infertility: a study in a Chinese population and a meta-analysis. Syst Biol Reprod Med 2015;61(4):222-227. DOI: 10.3109/19396368.2015.1017667.

23. Jin Q, Wang B, Wang J, et al. Erratum: association between TP53 gene Arg72Pro polymorphism and idiopathic infertility in southeast Chinese Han males. Syst Biol Reprod Med 2013;59(6):342-346. Systems Biology in Reproductive Medicine. 2014. 